\title{
WELDABILITY CHARTS FOR CONSTRUCTIONAL STEELS
}

\author{
John. C. Ion, Michael F. Ashby* \\ Division of Materials Science, Luleå University of Technology, 97187 Luleå, Sweden \\ *Department of Engineering, University of Cambridge, Cambridge CB2 1PZ, United Kingdom \\ john.ion@1tu.se
}

Despite extensive research, the weldability of steels is still a poorly understood concept. It may be defined in terms of various criteria: hardenability, sensitivity to cracking, limits on distortion etc. Even within the context of the hardenability of steels, different interpretations are applied, e.g. a maximum acceptable hardness or a microstructure containing a given amount of martensite. Unlike the mechanical behaviour of materials, which follows well established rules that can be used to define material performance indices, [Ashby, 2005] a numerical measure of weldability remains elusive. Attempts have been made previously to model the effect of weld energy input on the properties of the heat affected zone (HAZ) of carbon steels, which have led to the development of welding diagrams [Ion et al. 1984]. Such treatment enables weld properties to be displayed graphically in terms of the principal process variables. They help in understanding the underlying physical metallurgy of welding, but fall short of quantifying weldability.

Here we characterise weldability in terms of two quantities. A material index describes both the hardenability of the steel and the hardness of solid state transformation products, and is based on composition through the use of a simple carbon equivalent formula. A process index characterises the property of the welding process most relevant to weldability - its energy input. These indices are used as the axes of the weldability chart shown in Fig. 1.

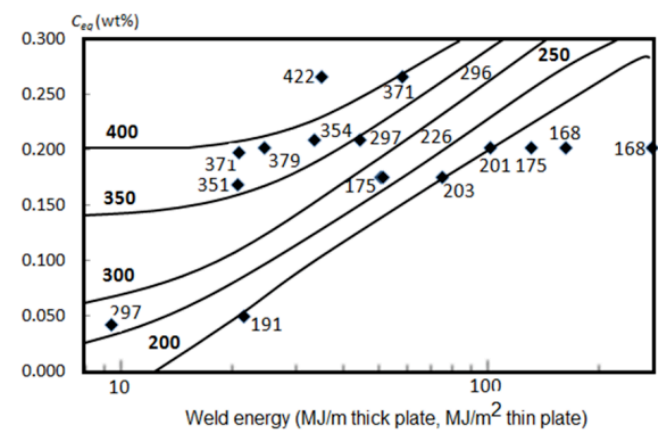

Figure 1. Chart showing hardness development in the HAZ of constructional steel welds. The axes are the process index (weld energy) and the material index $\left(C_{e q}\right)$.

Experimental data for the maximum heat affected zone hardness in welds produced by laser beam, metal inert gas, tungsten inert gas and submerged arc processes are shown as labelled data points in Fig. 1. Contours of constant hardness, calculated using a mathematical model, are also shown in Fig. 1. The mathematical model is seen to be a good predictor of the maximum hardness developed in the HAZ of constructional steels for the welding processes investigated. The charts provide a graphical display of the effects of variations in characteristic material and process indices on hardness and hardenability in constructional steels, and may be used in both education and industrial settings as a means of making an initial selection of process and material variables.

M.F. Ashby, Materials Selection in Mechanical Design. $4^{\text {th }}$ edition. 2011. J.C. Ion, M.F. Ashby and K.E. Easterling, Acta Metallurgica 32, 1984, 1949. 